\title{
Aqueous Extract of Terminalia chebula Induces Apoptosis in Lung Cancer Cells Via a Mechanism Involving Mitochondria- mediated Pathways
}

\author{
Meiling Wang ${ }^{2}$, Limin Yang ${ }^{1}$, Musi $\mathrm{Ji}^{3}$, Pengwei Zhao ${ }^{1}$, Peng Sun ${ }^{1}$, Ruixia Bai $^{4}$, Yunpeng \\ $\operatorname{Tian}^{1}$, Liping $\mathrm{Su}^{1}$ and Cunbao $\mathrm{Li}^{1 *}$ \\ ${ }^{I}$ Pathogenic Organisms and Immunology Lab; School of Basic Medical Science; Inner Mongolia Medical \\ University; PR China. ${ }^{2}$ Drug College; Inner Mongolia Medical University; PR China. ${ }^{3}$ Baotou Medical College. \\ ${ }^{4}$ Department of Clinical Laboratory; Inner Mongolia Peoples Hospital, Hohhot, PR China
}

\begin{abstract}
The current study was designed to evaluate the aqueous extract of Terminalia chebula activity, and the main pathway was detected on lung cancer by extracts of $\mathrm{T}$. chebula. Aqueous extract of $\mathrm{T}$. chebula was separated using a zeolite, and five fractions of $\mathrm{T}$. chebula extract were obtained and analyzed by ultraviolet (UV) and infrared (IR) spectroscopy. Antiproliferative activity was evaluated by 3-(4,5-dimethylthiazol-2-yl)-2,5-diphenyltetrazolium bromide (MTT) methods against human lung cancer (A549) and mouse lung cancer cell line LLC. T. chebula acts by regulating the Bcl-2 family protein-mediated mitochondrial pathway detected by western blot. Fraction 4 of the T. chebula extract showed much function and was thus studied further. Fraction 4 increased the activation of caspase3 , induced PARP cleavage, and promoted cytochrome c release into the cytoplasm. These data suggest that $\mathrm{T}$. chebula acts by regulating the Bcl-2 family protein-mediated mitochondrial pathway and provide evidence that $\mathrm{T}$. chebula deserves further investigation as a natural agent for treating and preventing cancer.
\end{abstract}

Key words: $T$. chebula, aqueous extract, infrared spectroscopy, apoptosis

\section{INTRODUCTION}

Terminalia chebula Retz. (T. chebula) is widely grown in tropical regions as a shade and ornamental tree (Manosroi et al. 2010), and it is important in Mongolian medicine. Dried galls of T. chebula are widely sold in the markets of Yun Nan Province in China and southeast Asian countries (Lee et al. 2005; Kim et al. 2012). In Mongolian medicine, T. chebula is called a "king drug". It is used as astringent, purgative, and food supplement. T. chebula extract (TE) has been reported to exhibit a variety of biological activities, including anticancer (Saleem et al.
2002), antidiabetic (Sairam et al. 2009), antimutagenic (Kaur et al. 1998), antibacterial (Malekzadeh et al. 2001), and anticaries effects (Jagtap and Karkera 1999). A total of 14 components of hydrolysable tannins, including gallic acid, chebulic acid, punicalagin, chebulanin, corilagin, neochebulinic acid, ellagic acid, chebulagic acid, chebulinic acid, 1,2,3,4,6-pentaOgalloyl- $\beta$-D-glucose, 1,6-di-O-galloyl-D-glucose, casuarinin, 3,4,6-tri-O-galloyl-D-glucose, and terchebulin, have been identified in $T$. chebula fruits (Lee et al. 2005).

On the molecular level, chemical information regarding the structure and composition of a

*Author for correspondence: licunbao5159@sina.com 
biological material can be effectively obtained by Fourier transform infrared (FTIR) spectroscopy (Yang et al. 2009), and therefore, the application of vibrational spectroscopy is expanding. As described by Noda (Noda 1989), conventional FTIR spectroscopy introduces a relatively slow external perturbation (e.g., electrical, thermal, chemical, mechanical) (Wu et al. 2008). Recently, with the development of the IR technique, much progress has been achieved. The effectiveness of various perturbation methods has been examined, different analytical probes have been surveyed, and new techniques (e.g., kernel analysis and augmented two-dimensional (2D) correlation, model-based correlation, moving window analysis, and global face angle) have been proposed. 2D-FTIR spectroscopy has been developed as an effective method for characterizing proteins and peptides, natural polymers and biomaterials, pharmaceuticals, food and agricultural products, and many other molecules of interest (Noda 2008). This noninvasive, convenient, and rapid technique has been applied to the study of various types of plant drugs, especially those used in traditional Chinese medicine (TCM), such as Radix saposhnikoviae and Radix codonopisis.

Apoptosis is the process of programmed cell death and is considered to be a key process for manipulation in cancer prevention ( $\mathrm{Li}$ et al. 2012). Activation of apoptosis occurs by extrinsic and intrinsic pathways. The extrinsic pathway is characterized by caspase- 8 cleavage, whereas the intrinsic pathway is characterized by cytochrome c release and caspase-9 activation ( $\mathrm{Lu}$ et al. 2011). During apoptosis, mitochondria play a key role, and in the mitochondria-dependent intrinsic apoptosis pathway, the Bcl-2 family members are very important players. The Bcl-2 family includes pro- and anti-apoptotic proteins that maintain a dynamic balance between the cell survival and death through interactions with each other and with other proteins (Ma et al. 2008).

Lung cancer is associated with more cancerrelated deaths than any other cancer and was the cause of 1.38 million deaths in 2008 alone (Cheng et al. 2008). In recent years, the incidence of lung cancer has continued to increase, and lung cancer is associated with a high mortality rate among cancer patients.

In this study, the lung cancer cell line A549 was used to investigate the activity of aqueous TE, and TE was analyzed by 2D-FTIR spectroscopy. In addition, the antitumor mechanisms of TE in lung cancer cells were investigated.

\section{MATERIAL AND METHODS}

\section{Materials}

Daiichi Sangyo Corporation (Osaka, Takayama, Japan). 3-(4,5-Dimethyl-2-thiazolyl) -2,5diphenyl-2H-tetrazolium bromide (MTT) and propidium iodide (PI) were purchased from Wako Pure Chemical Industries, Ltd. (Osaka, Japan). The Mitochondrial/Cytoplasm Fractionation Kit was obtained from BioVision (San Francisco, CA, USA). All of the primary antibodies used in the study were purchased from Cell Signaling Technology, Inc. (Danvers, MA, USA). Horseradish peroxidase (HRP)-linked antirabbit/ mouse (Cell Signaling Technology) or Alexa-488labeled goat anti-rabbit (Invitrogen, Carlsbad, CA, USA) IgG antibodies were used as secondary antibodies. The human lung cancer cell line A549 and mouse lung cancer cell line LLC were purchased from Chinese Academy of Sciences Cell Bank (Shanghai, China).

\section{Preparation of aqueous TE}

One kilogram of $T$. chebula was crushed to powder, and the powder was soaked in water for $24 \mathrm{~h}$ at approximately -30 to $-35^{\circ} \mathrm{C}$. The supernatant was collected by centrifugation at $4,000 \times \mathrm{g}$ for $10 \mathrm{~min}$ and separated using zeolite dialysis membranes with apertures of $55 \times 10^{4}$ $\mu \mathrm{m}, 40 \times 10^{4} \mu \mathrm{m}, 25 \times 10^{4} \mu \mathrm{m}$, and $1 \times 10^{4} \mu \mathrm{m}$. Different extract fractions were obtained using a UV spectrophotometer (Fayaz et al. 2011)and lyophilized.

\section{FTIR spectroscopy analysis}

A Spectrum GX FTIR spectrometer (PerkinElmer, Waltham, MA, USA) equipped with a deuterated triglycine sulfate detector was used with a resolution of $4 \mathrm{~cm}^{-1}$, a measuring range of $4000-400 \mathrm{~cm}^{-1}$, co-addition of 16 scans, and an optical path difference speed of $0.2 \mathrm{~cm}^{-1} / \mathrm{s}$. The interference of $\mathrm{H}_{2} \mathrm{O}$ and $\mathrm{CO}_{2}$ was minimized during scanning. The 50-886 Temperature Controller (Love Control Co. Beijing, China) was used with an increasing temperature rate of $2^{\circ} \mathrm{C} /$ min over a temperature range of $50-120^{\circ} \mathrm{C}$, with a sampling frequency of scanning every $10^{\circ} \mathrm{C}$. Ten-gram TE samples were prepared with ether. The different extract fractions were then 
used to obtain their FTIR spectra. The spectral data were processed using Spectrum v3.02 software (Perkin-Elmer) to compare the similarities between the two FTIR spectra (or one spectrum with a series of spectra) using mathematical correlation coefficients.

\section{Cell culture}

The cancer cells were grown as a monolayer in RPMI-1640 (Hyclone, Logan, UT, USA) containing $10 \%$ fetal bovine serum. Cells were maintained at $37^{\circ} \mathrm{C}$ in a humidified incubator under a $5 \% \mathrm{CO}_{2}$ atmosphere.

\section{Cell proliferation assay}

Cell proliferation was analyzed using the MTT assay. Cells were seeded in 96-well plates at densities of 1000-3000 cells/well and incubated for different time periods with or without different concentrations of TE. At different time points, 10 $\mu \mathrm{L}$ of MTT solution $(5 \mathrm{mg} / \mathrm{mL})$ was added to each well. The plates were incubated for an additional 4 $\mathrm{h}$ at $37^{\circ} \mathrm{C}$. The medium was removed and $200 \mu \mathrm{L}$ DMSO was added to each well and pipetted repeatedly to dissolve the formazan. The absorbance of each well was measured at $570 \mathrm{~nm}$ with a microplate reader (Tecan Group Ltd., Ma"nnedorf, Switzerland).

\section{RNA extraction and qRT-PCR}

Total RNA was isolated from cells using the RNeasy kit (Qiagen, Hilden, Germany). The RNA content of samples was too low to be accurately quantified by spectrometry, and thus, $6.5-\mu \mathrm{L}$ RNA aliquots were amplified. All RNA samples were treated with RNasefree DNase I to remove any possible genomic DNA contamination. For amplification of the targets, RT and PCR were run in two separate steps (TaKaRa, Inc., Dalian, China). Primers showed in Table1.

Table 1 - Primers used in this study.

\begin{tabular}{|c|c|c|}
\hline GAPDH & $\begin{array}{l}\text { sense } \\
\text { anti-sense }\end{array}$ & $\begin{array}{l}\text { GGTGAAGGTCGGAGTCAACGGA } \\
\text { GAGGGATCTCGCTCCTGGAAGA }\end{array}$ \\
\hline Bax & $\begin{array}{l}\text { sense } \\
\text { anti-sense }\end{array}$ & $\begin{array}{l}\text { GGATGATTGCCGCCGT } \\
\text { CCCAGTTGAAGTTGCCGT }\end{array}$ \\
\hline bcl-2 & $\begin{array}{l}\text { sense } \\
\text { anti-sense }\end{array}$ & $\begin{array}{l}\text { TGCACCTGACGCCCTTCAC } \\
\text { AGACAGCCAGGAGAAATCAAACAG }\end{array}$ \\
\hline bcl-xl & $\begin{array}{l}\text { sense } \\
\text { anti-sense }\end{array}$ & $\begin{array}{l}\text { GTAAACTGGGGTCGCATTGT } \\
\text { TGCTGCATTGTTCCCATAGA }\end{array}$ \\
\hline
\end{tabular}

\section{Western blotting}

Cells were harvested, washed with PBS at $37^{\circ} \mathrm{C}$, and lysed with a phenylmethanesulfonyl fluoride lysis buffer (Invitrogen). After centrifugation at
$13,200 \times \mathrm{g}$ for $30 \mathrm{~min}$, the protein content of the supernatant was determined using the bicinchoninic acid reagent (Sigma). Total protein $(50 \mu \mathrm{g})$ from each sample was electrophoresed on a 10\% SDS-PAGE gel and transferred to a polyvinylidene fluoride membrane (Millipore, Billerica, MA, USA). The membranes were blocked with PBS containing 5\% fat-free milk (Becton Dickinson, Franklin Lakes, NJ, USA) and $0.1 \%$ Tween-20 (Sigma) for $30 \mathrm{~min}$ at room temperature and then incubated with primary antibody for at least $1 \mathrm{~h}$ at room temperature or overnight at $4^{\circ} \mathrm{C}$. The membranes were washed three times with PBS containing 0.1\% Tween 20, incubated with peroxidase-conjugated secondary antibodies (Millipore), and developed using the ECL reagent (Pierce, Rockford, IL, USA). And the photograph was obtain by Imaging Systems (UVP, USA)

\section{Statistical analysis}

All experiments were performed at least in triplicate. Data are presented as mean \pm standard deviation (SD), and $\mathrm{p}$ values were calculated using the Student's $t$-test accompanied by analysis of variance (ANOVA) where appropriate.

\section{RESULTS}

\section{TE fractions by $U V$ analysis}

An aqueous extraction method was used to obtain different fractions of TE. The crude extract was separated, and UV spectroscopy analysis was used to obtain five extract fractions (named 1, 2, 3, 4, and 5) with different optical densities at the same wavelength (Fig. 1).

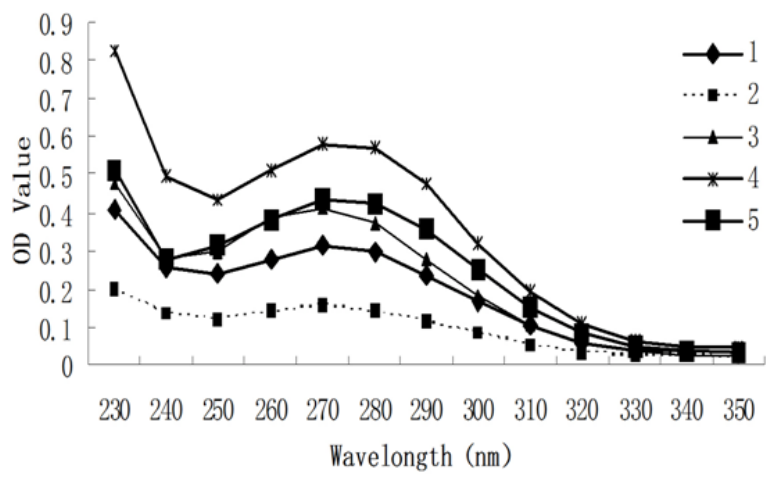

Figure 1 - Five fractions of $T$. chebula extract according to UV spectroscopy analysis. 


\section{FTIR analysis of TE fractions}

To analyze the contents of the five extract fractions, FTIR spectroscopy was used, and the resulting spectra are shown in Figure 2. The
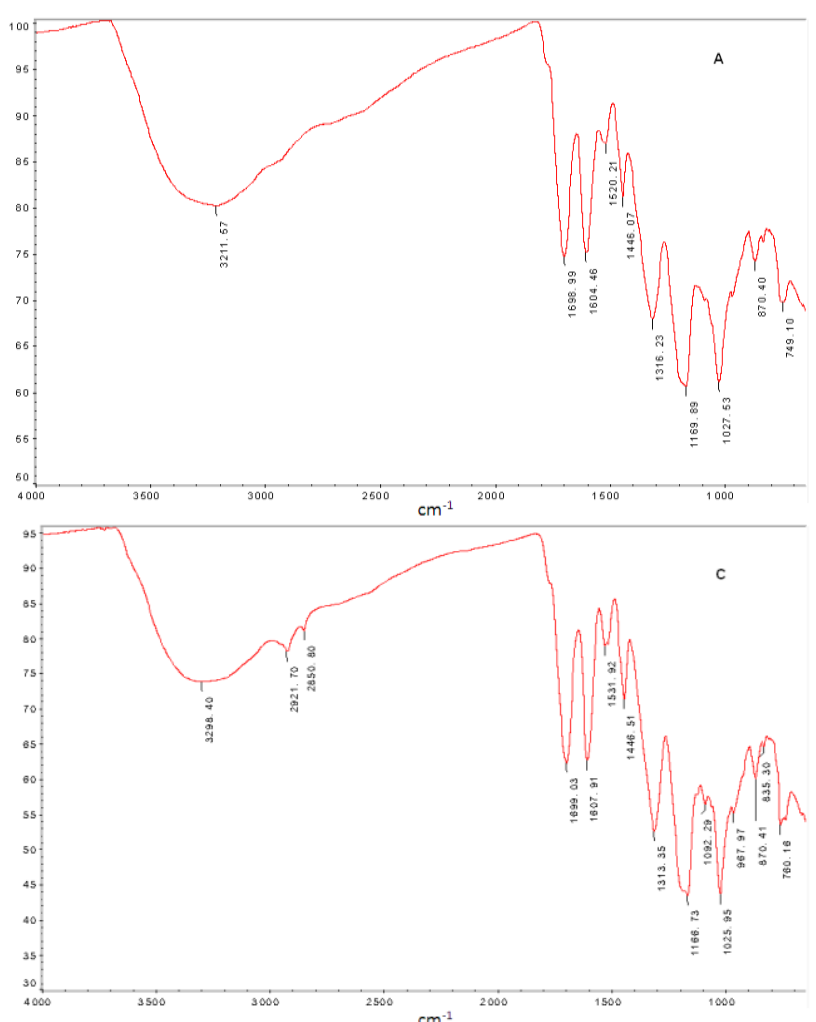

spectrum for fraction 3 showed differences from those of the other four fractions, with two peaks at $2921.70 \mathrm{~cm}^{-1}$ and $2850.80 \mathrm{~cm}^{-1}$.
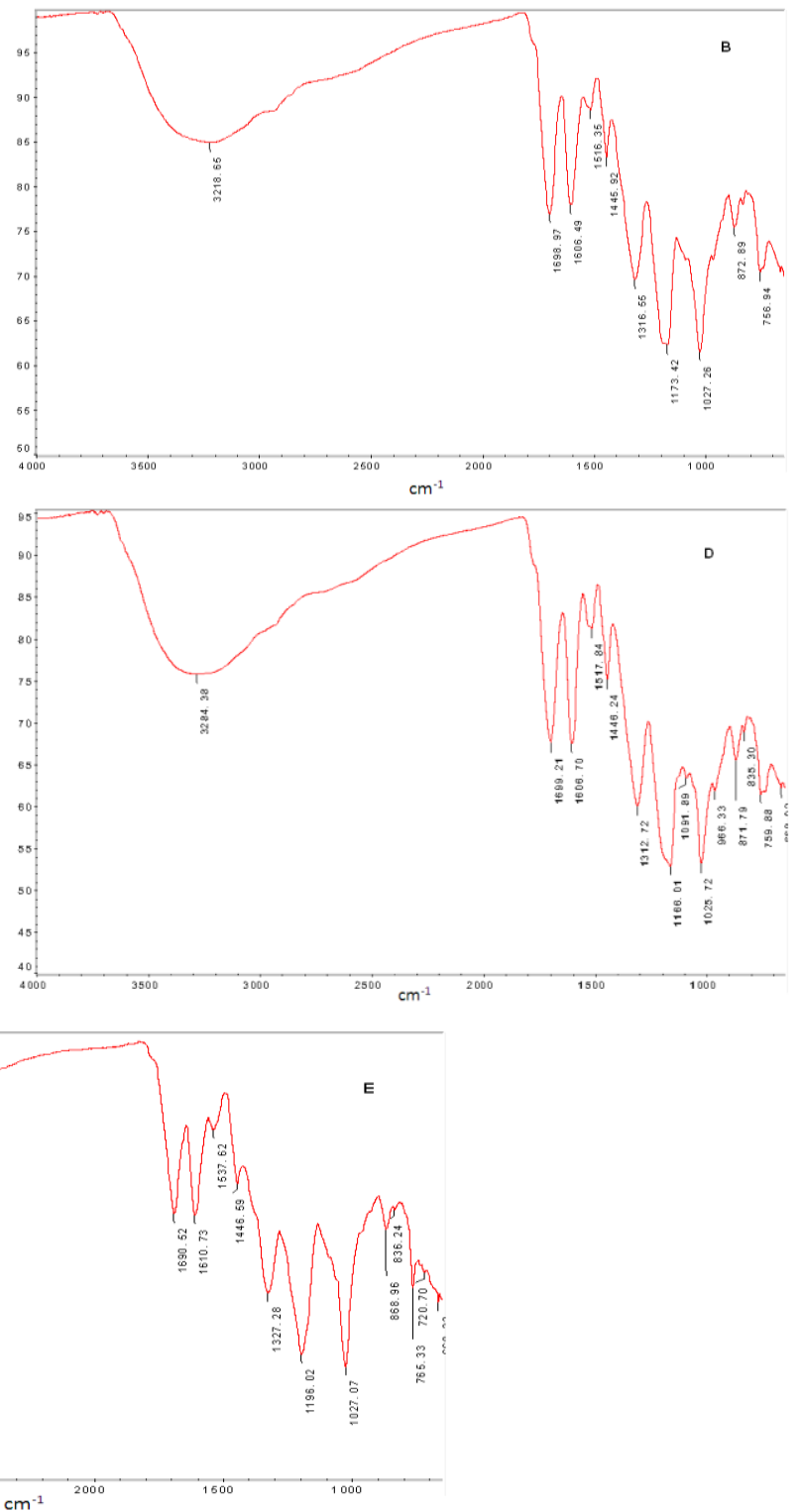

Figure 2 - 2D-FTIR analysis of five (A to E) Terminalia chebula extract fractions.

A549 cell proliferation upon exposure to $T E$ fractions

To determine the activity of the TE fractions, cells of the A549 lung cancer cell line were exposed to $500 \mu \mathrm{g} / \mathrm{mL}$ of each fraction and the resulting inhibition of cell growth was examined using the MTT assay at 48 h. Fraction 3 exhibited the lowest rate of growth inhibition, and fraction 4 exhibited the highest rate among the five fractions (Fig. 3A).
Therefore, fraction 4 was selected for further study.

To determine the optimal concentration of TE fraction 4 for inhibition of A549 cell growth, cells were exposed to four concentrations of fraction 4 $(125,250,500$, and $1000 \mu \mathrm{g} / \mathrm{mL})$. A concentration of $500 \mu \mathrm{g} / \mathrm{mL}$ was associated with the most inhibition of A549 cell growth (Fig. 3B), and the optimal time for growth inhibition was $48 \mathrm{~h}$ (Fig. 3C). 
Effects of TE fraction 4 on expression of Bcl-2 proteins

To further investigate the effect of fraction 4 on A549 cells, the mRNA and protein expression levels of Bcl-2 proteins (Bcl-2, Bcl-xL, and Bax) were examined upon exposure of cells to different
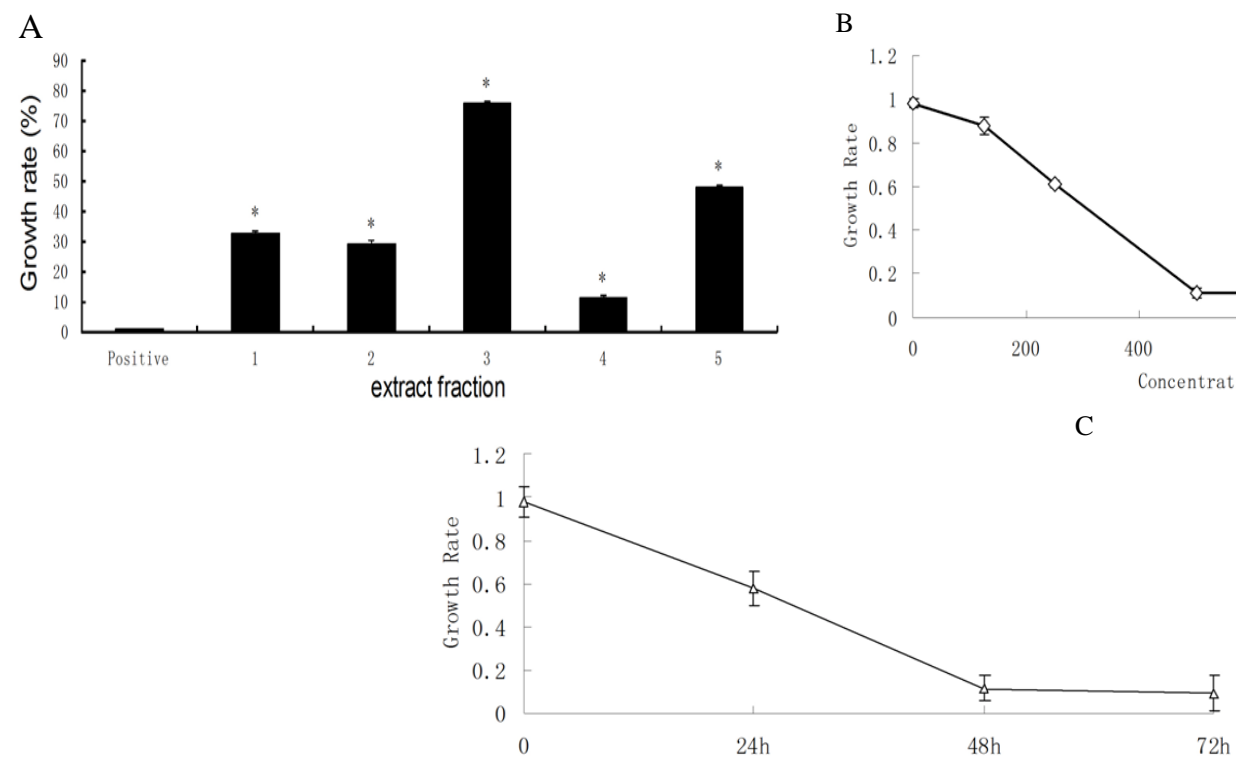

Figure 3 - Cell proliferation assay. A: Growth rates of A549 cells by the five T. chebula extract fractions $(500 \mu \mathrm{g} / \mathrm{mL})$ at $48 \mathrm{~h}$. B: Growth rates of A549 cells by fraction $4(125,250,500$, and 1000 $\mu \mathrm{g} / \mathrm{mL})$ at $48 \mathrm{~h}$. C: Growth rates of A549 cells by $50 \mu \mathrm{g} / \mathrm{mL}$ fraction 4 at $0,24,48$, and $72 \mathrm{~h}$.

A

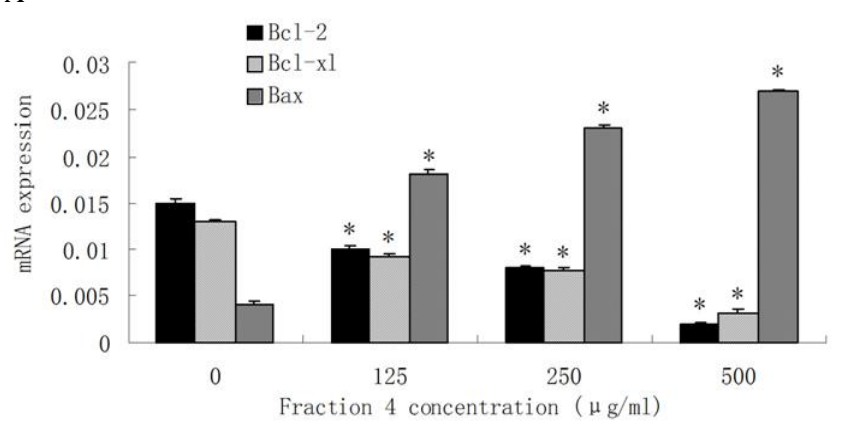

B

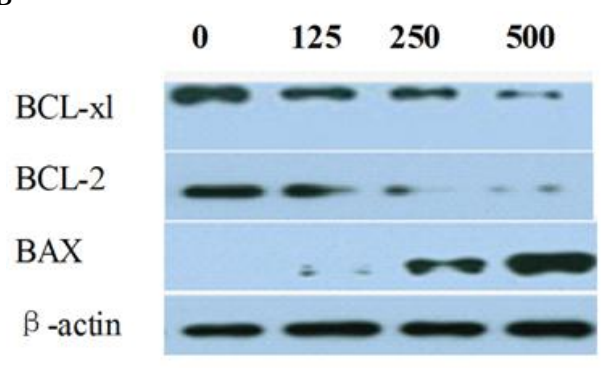

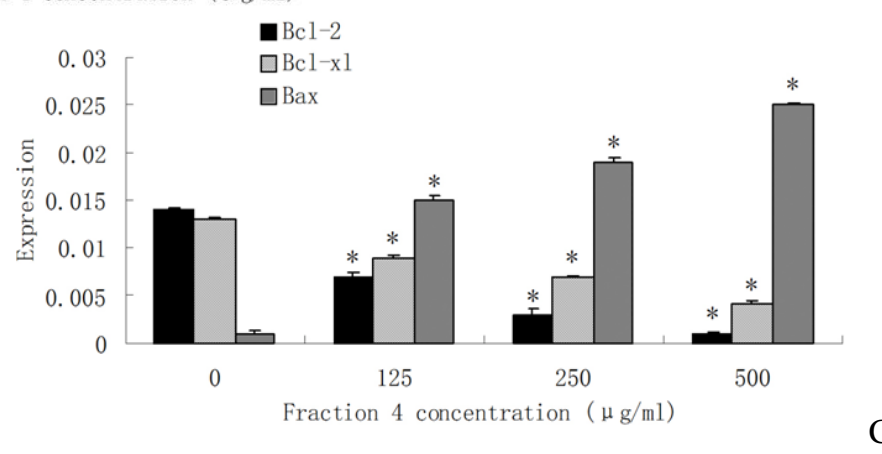

Figure 4 - mRNA and protein expression of proteins of the Bcl-2 family (Bcl-2, Bcl-xl, and Bax) after treatment of A549 cells with $T$. chebula extract fraction $4(125,250,500$, and $1000 \mu \mathrm{g} / \mathrm{mL})$. A: mRNA expression of Bcl-2, Bcl-xl, and Bax according to qPCR . B; mRNA expression of Bcl2, Bcl-xl, and Bax. C: Protein expression of Bcl-2, Bcl-xl, and Bax according to western blot analysis. D: Protein expression of Bcl-2, Bcl-xl, and Bax. 
Effects of TE fraction 4 on caspase-3, PARP, and cytochrome c expression

To determine whether caspase- 3 and PARP are involved in apoptosis mediated by TE fraction 4, their expression levels were analyzed by western blotting. As shown in Figure 5, caspase-3 cleavage increased as the concentration of fraction 4 increased. Cleaved PARP was also activated by fraction 4, and cytochrome c, another apoptotic regulatory protein, was detected by western blot analysis. Analysis according to different concentrations showed the release of cytochrome $\mathrm{c}$ from the mitochondria into the cytoplasm (Fig. 6). $\begin{array}{llll}0 & 125 & 250 & 500\end{array}$

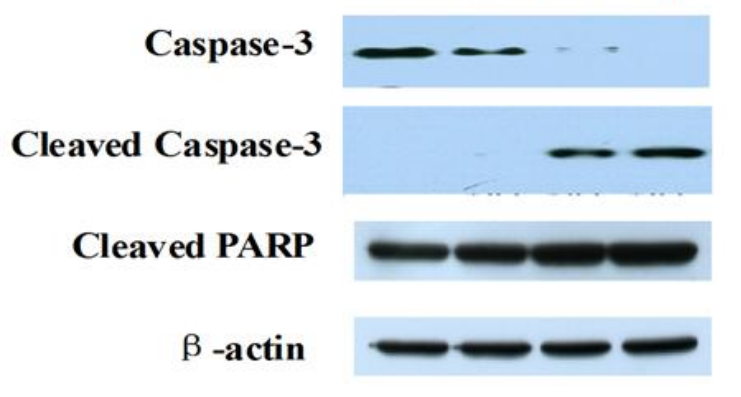

Figure 5 - Effects of $T$. chebula extract fraction 4 (125, 250, 500, and $1000 \mu \mathrm{g} / \mathrm{mL}$ ) on caspase-3 expression, caspase- 3 cleavage, and PARP cleavage according to western blot analysis.
A

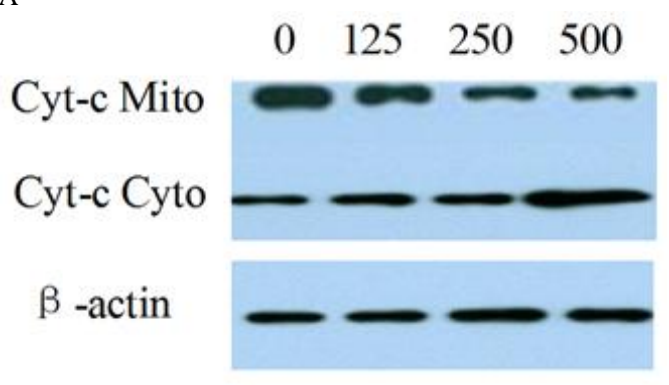

B

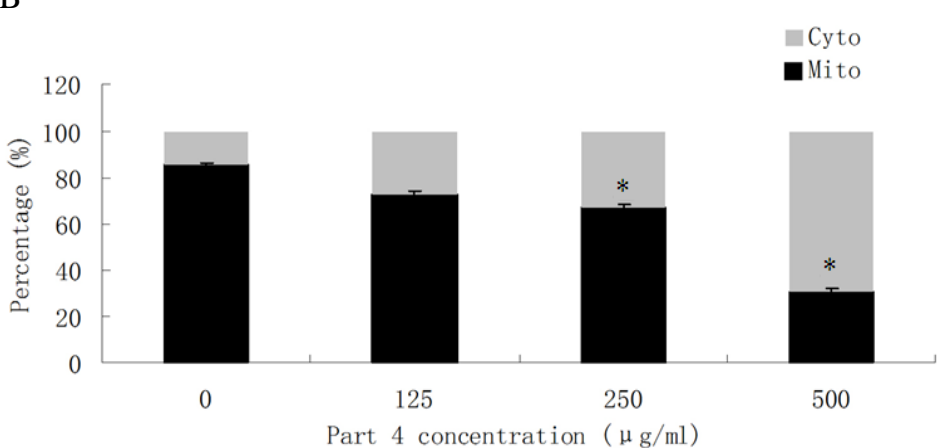

Figure 6 - Effects of $T$. chebula extract fraction $4(125,250,500$, and $1000 \mu \mathrm{g} / \mathrm{mL})$ on the levels of cytochrome-c in mitochondria and cytosol. A: The spectra analyzed by western blotting. B: The percentage of cytochrome-c in mitochondria vs in cytosol. *Compared to the blank group, the different was significantly $(\mathrm{P}<0.05)$.

\section{DISCUSSION}

Terminalia chebula is not only used widely in TCM but also in Mongolian medicine to treat different ailments for a long time. Recently, many biological activities of $T$. chebula, such as anticancer, antidiabetic, antimutagenic, antibacterial, antifungal, and antiviral effects have been reported in the literature (Saleem et al. 2002; Cheng et al. 2003; Ponnusankar et al. 2011). The product of $T$. chebula decoction has been shown to inhibit bacterial growth as well as cancer (Kim et al. 2012). Therefore, T. chebula is very useful in TCM and Mongolian medicine. For use in TCM, T. chebula was boiled in water, not in organic solutions, and the mixture obtained by decoction of $T$. chebula was primarily used (Zhang et al. 1997; Cheng et al. 2003). In this study TE was prepared in water at low temperature and separated into five fractions according to molecular weight by UV spectroscopy. Therefore, each of the five fractions was also a mixture.

Currently, the best method for analyzing mixtures may be FTIR spectroscopy (Tu et al. 2011), because this technique does not require complex sample treatment. In this study, the five fractions of TE were analyzed by FTIR. The spectrum for fraction 3 had two peaks at $2921.70 \mathrm{~cm}^{-1}$ and $2850.80 \mathrm{~cm}^{-1}$, which differed from the spectra for the other four fractions. These two peaks represent the protein and may influence the activity of fraction 4.

$T$. chebula is a potent inducer of apoptosis in lung cancer cell lines (Saleem et al. 2002). In our study, we found that aqueous TE could inhibit the growth lung cancer cell lines and caused cell morphology changes as well (data not shown). The MTT assay results showed that the inhibition of cancer cell viability was time- and dose-dependent.

Apoptosis induced by some anticancer agents constitutes one aspect of their treatment effect. 
Two major pathways involved in the process have been investigated in great depth (Gustafsson and Gottlieb 2007). One pathway is the death-receptor pathway, and the other is the mitochondrial pathway. The latter has been considered an important mediator of cell apoptosis in mammals (Song et al. 2011). In the mitochondrial pathway, Bcl-2 family members, including the antiapoptotic Bcl-2 and Bcl-xl and the pro-apoptotic Bax protein are responsible for regulating apoptosis in different situations (Brunelle and Letai 2009). In this study, TE induced reduced expression of Bcl-2, Bcl-xl and greater expression of Bax. Therefore, TE can promote A549 cell apoptosis. We studied the mechanism of apoptosis induced by TE fraction $4(0-500 \mu \mathrm{g} / \mathrm{mL})$, which showed anti-proliferative activity in A549 cells. Apoptosis is initiated through the mitochondrial pathway under physiological conditions such as oxidative stress, mitochondrial disturbance, and DNA damage (Gotoh et al. 2012) (another important key player in the mitochondrial pathway of apoptosis). This pathway is involved in the permeabilization of the outer mitochondrial membrane, which facilitates cytochrome c release into the cytoplasm. Cytochrome $\mathrm{c}$ binds the caspase adaptor apoptotic protease-activating factor-1, thereby triggering the apoptotic cascade by activating procaspase 9 and forming an apoptosome complex (Jang et al. 2002). This apoptosome, in turn, activates the downstream effectors caspases-3, -6 , and -7 , leading to apoptosis. The typical executioners of apoptosis are proteolytic enzymes called caspases (Floros et al. 2006). Our results clearly demonstrate that TE fraction 4 increased the activation of caspase-3, induced PARP cleavage, and promoted cytochrome $\mathrm{c}$ release into the cytoplasm. In addition, the PI-Annexin- $\mathrm{V}$ staining assay and western blot analysis confirmed that A549 cell apoptosis was regulated by caspase-3, and therefore, caspase activation may be one of the primary mechanisms by which TE fraction 4 induces apoptosis.

Given that aqueous TE may play a novel role as a complementary medicine in lung cancer treatment, future research on its anticancer mechanisms is warranted. We also studied the activity of TE in LLC mouse lung cancer cells and normal mouse lung cells (data not shown), and the results in LLC cells showed the same effect of TE as in A549 cells. However, aqueous TE extract did not show this effect on normal mouse lung cells.

\section{CONCLUSION}

In conclusion, our results show that aqueous TE can be separated into five fractions by UV spectroscopy and that the five fractions each had a unique FTIR spectrum. The IR spectrum for fraction 3 showed significant differences from those of the other four fractions, and TE fraction 4 inhibited cell proliferations by inducing apoptosis and cell-cycle arrest in A549 breast cancer cells. These results contribute to the understanding of the anticancer activity of $T$. chebula.

\section{ACKNOWNLEDGEMENT}

This work was sport by baiwangongcheng (No. kjbw2012002) Inner Mongolia medical university.

\section{REFERENCES}

Brunelle JK and Letai A. Control of mitochondrial apoptosis by the Bcl-2 family. J Cell Sci. 2009; 122(Pt 4): 437-441.

Cheng HY, Lin TC, Yu KH, Yang CM, Lin CC. Antioxidant and free radical scavenging activities of Terminalia chebula. Biol Pharm Bull. 2003; 26(9): 1331-1335.

Cheng YL, Lee SC, Harn HJ, Huang HC, Chang WL. The extract of Hibiscus syriacus inducing apoptosis by activating p53 and AIF in human lung cancer cells. Am J Chin Med. 2008; 36(1): 171-184.

Fayaz AM, Girilal M, Venkatesan R, Kalaichelvan PT. Biosynthesis of anisotropic gold nanoparticles using Maduca longifolia extract and their potential in infrared absorption. Colloids Surf B Biointerfaces. 2011; 88(1): 287-291.

Floros KV, Thomadaki H, Florou D, Talieri M, Scorilas A. Alterations in mRNA expression of apoptosisrelated genes BCL2, BAX, FAS, caspase-3, and the novel member BCL2L12 after treatment of human leukemic cell line HL60 with the antineoplastic agent etoposide. Ann N Y Acad Sci. 2006; 1090: 89-97.

Gotoh M, Sano-Maeda K, Murofushi H, MurakamiMurofushi K. Protection of Neuroblastoma Neuro2A Cells from Hypoxia-Induced Apoptosis by Cyclic Phosphatidic Acid (cPA). PLoS One. 2012; 7(12): e51093.

Gustafsson AB, Gottlieb RA. Bcl-2 family members and apoptosis, taken to heart. Am J Physiol Cell Physiol. 2007; 292(1): C45-51.

Jagtap AG, Karkera SG. Potential of the aqueous extract of Terminalia chebula as an anticaries agent. $J$ Ethnopharmacol. 1999; 68(1-3): 299-306. 
Jang MH, Shin MC, Shin HS, Kim KH, Park HJ, Kim $\mathrm{EH}$, et al. Alcohol induces apoptosis in TM3 mouse Leydig cells via bax-dependent caspase-3 activation. Eur J Pharmacol. 2002; 449(1-2): 39-45.

Kaur S, Grover IS, Singh M. Antimutagenicity of hydrolyzable tannins from Terminalia chebula in Salmonella typhimurium. Mutat Res. 1998; 419(1-3): 169-179.

Kim JH, Koo YC, Hong CO, Yang SY, Jun W, Lee KW. Mutagenicity and oral toxicity studies of Terminalia chebula. Phytother Res. 2012; 26(1): 3947.

Lee HS, Won NH, Kim KH, Lee H, Jun W, Lee KW. Antioxidant effects of aqueous extract of Terminalia chebula in vivo and in vitro. Biol Pharm Bull. 2005; 28(9): 1639-1644.

Li CJ, Tsang SF, Tsai CH, Tsai HY, Chyuan JH, Hsu HY. Momordica charantia Extract Induces Apoptosis in Human Cancer Cells through Caspase- and Mitochondria-Dependent Pathways. Evid Based Complement Alternat Med. 2012; 2012: 261971.

Lu Y, Zhang BY, Jia ZX, Wu WJ, Lu ZQ. Hepatocellular carcinoma HepG2 cell apoptosis and caspase- 8 and Bcl-2 expression induced by injectable seed extract of Coix lacryma-jobi. Hepatobiliary Pancreat Dis Int. 2011; 10(3): 303-307.

Ma H, Lai F, Xie H, Wang J, Wang H. Involvement of the Bcl-2 family members in Pinus massoniana bark extract induced apoptosis in HeLa cells. Phytother Res. 2008; 22(11): 1472-1476.

Malekzadeh F, Ehsanifar H, Shahamat M, Levin M, Colwell RR. Antibacterial activity of black myrobalan (Terminalia chebula Retz) against Helicobacter pylori. Int J Antimicrob Agents. 2001; 18(1): 85-88.

Manosroi A, Jantrawut P, Akazawa H, Akihisa T, Manosroi J. Biological activities of phenolic compounds isolated from galls of Terminalia chebula Retz. (Combretaceae). Nat Prod Res. 2010; 24(20): 1915-1926.

Noda I. Two-Dimensional Infrared Spectroscopy. J Am Chem Soc. 1989;111: 8116-8118.
Noda I. Recent advancement in the field of twodimensional correlation spectroscopy. J Mol Struct. 2008; 883-884.

Ponnusankar S, Pandit S, Venkatesh M, Bandyopadhyay A, Mukherjee PK. Cytochrome P450 inhibition assay for standardized extract of Terminalia chebula Retz. Phytother Res. 2011; 25(1): 151-154.

Sairam TN, Dey P, Mangamma G, Nath TK, Sundar CS. Temperature dependence of phonon modes in nanocrystalline $\mathrm{La} 0.67 \mathrm{ca} 0.33 \mathrm{MnO} 3$ as observed by infrared spectroscopy. J Nanosci Nanotechnol. 2009; 9(9): 5471-5475.

Saleem A, Husheem M, Harkonen P, Pihlaja K. Inhibition of cancer cell growth by crude extract and the phenolics of Terminalia chebula retz. fruit. $J$ Ethnopharmacol. 2002; 81(3): 327-336.

Song XQ, Guo YL, Wang BG, Sun SJ, Yao R. Y. Effect of tagalsin on p53 and Bcl-2 expression in hepatoma $\mathrm{H}(22)$ tumor-bearing mice. Zhonghua Zhong Liu Za Zhi. 2011; 33(7): 499-503.

$\mathrm{Tu}$ Y, Liu J, Zhang J. Application of near-infrared spectroscopy technology in quality control of TCM manufacturing process. Zhongguo Zhong Yao Za Zhi. 2011; 36(17): 2433-2436.

Wu YW, Sun SQ, Zhou Q, Leung HW. Fourier transform mid-infrared (MIR) and near-infrared (NIR) spectroscopy for rapid quality assessment of Chinese medicine preparation Honghua Oil. J Pharm Biomed Anal. 2008; 46(3): 498-504.

Yang P, Song P, Sun SQ, Zhou Q, Feng S, Tao JX. Differentiation and quality estimation of Cordyceps with infrared spectroscopy. Spectrochim Acta A Mol Biomol Spectrosc. 2009; 74(4): 983-990.

Zhang X, Chen C, He S, Ge F. Supercritical-CO2 fluid extraction of the fatty oil in Terminalia chebula and GC-MS analysis. Zhong Yao Cai. 1997; 20(9): 463 464. 